\title{
Experiences of Discrimination and Its Effect on Life Satisfaction: Understanding Differences within Subgroups of Foreign Spouses from Multicultural Families in Korea
}

\author{
Hyemee $\mathrm{Kim}^{1}$ \& Seojin Won ${ }^{2}$ \\ ${ }^{1}$ Department of Social Welfare, Incheon National University, Incheon, Korea \\ ${ }^{2}$ Department of Social Welfare, Daegu Cyber University, Gyeongsan, Korea \\ Correspondence: Seojin Won, Department of Social Welfare, Daegu Cyber University, Daegudaero 201 \\ Jillyangeup, Gyeonsgan 712-714, Korea. Tel: 82-53-850-4076. E-mail: wonseojin@gmail.com
}

\author{
Received: July 18, 2015 Accepted: August 5, 2015 Online Published: August 28, 2015 \\ doi:10.5539/ass.v11n26p64 URL: http://dx.doi.org/10.5539/ass.v11n26p64
}

\begin{abstract}
This study aims to examine the effect of perceived discrimination on life satisfaction of the foreign wives from multicultural families in Korea. In particular, this study aims to understand whether these experiences and the impact of such experiences on their life satisfaction differ by spouses' ethnic background. Using the data from 'National Survey of Multicultural Families 2009', analyses were conducted on 16,064 foreign wives living in Korea. The findings show that perceived discrimination is significantly associated with low life satisfaction that those reporting of having experienced more discriminatory events were less satisfied with their life in general. The findings also show that ethnic group differences indeed exist in migrants' exposure to discriminatory events and in the level of life satisfaction. These findings imply that social work practitioners and scholars need to recognize such differences in understanding the marriage migrants and that one-size fits all approach does not work when working with the population.
\end{abstract}

Keywords: discrimination, life satisfaction, ethnic difference, multicultural family in Korea

\section{Introduction}

A recent study conducted by Ministry of Gender Equality and Families [MOGEF] reported that approximately $41.3 \%$ of the foreign spouses have experienced some type of discrimination in their daily lives. According to the report, male spouses reported of being exposed to discriminatory events more frequently than the female spouses (42.2\% vs. $41.1 \%$ ), and that while over $50 \%$ of the spouses from Southern Asian countries, Southeast Asian countries, and Pakistan reported of having experienced the events, the portion was much smaller among those spouses from U.S. and Japan (MOGEF, 2013). Such report paints a rather bleak picture of reality for foreigners both currently residing and planning to reside in Korea, and puts Korean society to shame as it prides in being a globalized nation welcoming foreigners from all across the world. Though one may argue discrimination is an inevitable part of human life that has existed all throughout human history, it nevertheless remains as one of the central social problems facing societies in all forms across the globe.

For Korean society, it is particularly important to address the issue of discrimination as a social issue as it is in the process of establishing its identity as a multicultural, ethnically diverse society celebrating and embracing differences and diversity. The issue of discrimination, in fact, has long been a social agenda and has been discussed in many areas especially in relation to gender, age, and disability. In contrast, discrimination based on race or ethnicity has garnered relatively less public attention as Korean society has remained relatively an ethnically homogeneous society, or at least it claimed its identity as such for a long period of time. However, with changing population make up of Korea and an ever increasing number of foreigners residing in the country, it has surfaced as a central, critical social issue that warrants attention from public. With racial discrimination being identified as one of the causal factors of broader social problems such as disparity in income, education, and health as well as poverty and illiteracy (Zastrow, 1999), understanding how racial discrimination takes form and affects the ethnic minorities is now an urgent task for Korean society.

Despite its importance, effort to understand how discriminatory experiences affect individuals from ethnic minority groups has been minimal in Korea. Among hundreds of studies being published annually addressing 
various issues of foreign spouses of multicultural families, the number of studies that investigate discrimination beyond simple statistics and rates is handful. This study was thus set out to fill this gap in literature on foreign spouses of multicultural families by examining the relationship between discriminatory experiences and life satisfaction; in addition, this study also investigates whether the relationship is consistent across spouses from different ethnic groups. As foreigners are often treated to be a homogeneous group, often resulting in uniform approach in policy and practice, this study aims to provide an empirical evidence of within-group differences, asserting the importance of approaching foreigners as a diverse group with different needs.

\section{Literature Review}

\subsection{Perceived Racial/Ethnic Discrimination}

Race-ethnic discrimination refers to "practices and actions of dominant race-ethnic groups that have a differential and negative impact on subordinate race-ethnic groups" (Feagin \& Eckberg, 1980, p. 9). Commonly identified as a core concept in understanding diversity or a lack of it (Pincus, 1996), it exists at multiple levels in society from personal to structural level. Structural and institutional discrimination are similar in that they refer to policies of dominant race/ethnic group and behaviors of those involved that are either intended or unintended, but consequently have differential and/or harmful effect on the minority group. Discrimination at the personal level mainly refers to specific behavior of individuals with an intention to have harmful effect on those targeted (Pincus, 1996). The consequence of discriminatory actions is also known to differ by its type. Discrimination at the structural level is invoked as the primary cause of racial/ethnic gaps in income, employment, housing, and such (Jones, 2000), while discrimination at the personal level has been associated with various adverse psychological, behavioral, and health outcome for individuals of all ages (Sanders-Phillips, 2009; Finch \& Vega, 2003; Brody et al., 2006). As ethnic minorities are perpetually exposed to discriminatory experiences in their daily life, discriminations based on one's race or ethnicity undoubtedly function as a significant risk factor (Prelow, Mosher, \& Bowman, 2006) and a chronic stressor (Harrell, 2000), which over time can lead to deteriorated health and mental health, affecting all aspects of their life (Selye, 1956, as quoted in Prelow et al., 2006).

Ethnic minorities in Korea are particularly vulnerable to discrimination as Choi (2007) explained, Koreans exhibit a strong tendency to categorize people into 'us' and 'them' based on lineage by blood. Rooted in familism, Koreans emphasize lineage and easily consider who do not share the lineage as outsiders (Choi, 2007), and this has resulted in outright discrimination against those who are perceived as the outsiders. As described above, almost half of the foreign spouses responded that they have experienced discriminatory events during their stay in Korea because of their race or ethnicity (MOGEF, 2013), and this number has increased quite significantly from $36 \%$ in the national study conducted in 2009. Children born between foreign spouse and Korean parent are no exception to this as about $13.8 \%$ of the children being surveyed in 2012 also recalled unpleasant experiences of being discriminated by their peers, neighbors, teachers, and even their extended family members (MOGEF, 2013).

Empirical studies demonstrating the association between discriminatory experiences and individuals' developmental, psychological, behavioral, mental, and physical health are rather copious (Phinney, Madden, \& Santos, 2006; Pavalko, Mossakowski, \& Hamilton, 2003; Brody et al., 2006; Prelow et al., 2006; Yoo \& Lee, 2008; Hwang \& Goto, 2009; Brown \& Chu, 2012) in other countries, however, studies examining such relation among foreigners residing in Korea are quite scarce. There are very few studies that examined the role of discriminatory experiences in explaining foreigners' well-being (Kim, 2007; Cho, 2011; Kim, Won, \& Choi, 2011; Jin, Bae, \& Hyun, 2011; Choi, 2012). For example, Kim et al. (2011) examined the association between perceived discrimination and psychological distress among children of multicultural families and found supportive evidence that such experiences elevated the level of depression and anxiety among children. Kim (2007) in her study of children of foreign migrant workers in Korea also yielded a similar finding that perceived discrimination was also negatively associated with their mental health. Choi (2012)'s study on Korean-Japanese adolescents in Korea also reported that the experiences of discrimination were positively related to problematic behaviors and aggression while it was negatively associated with their self-esteem. Though these studies provide an enlightening and supportive finding, emphasizing the harmful effect of discrimination on its ethnic minority individuals' well-being, their findings cannot be generalized to older population as these studies mainly investigated the experiences of children. Jin et al.'s (2011) study also limited their participants to Chinese students studying in Korea, a different population from other foreigners such as foreign spouses of Korean families. With no empirical studies on foreign spouses presently available, it is difficult to understand how these foreign residents are faring in Korean society, and it is thus imperative to explore the discriminatory experiences of foreign spouses and understand how they affect their life in general. 


\subsection{Life Satisfaction}

Life satisfaction is in fact, the most extensively investigated topic in understanding psychological well being of different populations, and can be defined as a "global assessment of a person's quality of life according to his and/or her chosen criteria" (Shin \& Johnson, 1978, as quoted in Vohra \& Adair, 2000, p. 111). Satisfaction of life depends not only on what people have, but on criteria that people choose themselves and how they judge their own achievement (Kalaver, 1998). Studies on life satisfaction of general population as well as more specific subpopulations have been conducted since 1950's, beginning with Wessman's (1956, as quoted in Clemente \& Sauer, 1976) doctoral dissertation on satisfaction and happiness in the U.S. Since then, a profuse amount of studies have been conducted to examine life satisfaction of more specific sub-populations such as the elderly, children, women, and the employed and their relationships with various constructs of mental health and/or physical health (Alston \& Dudley, 1973; Alston, Lowe, \& Wrigley, 1974; Palmore \& Luikart, 1972; Horley, 1984; Inglehart, 1990; Kalaver, 1998; Bruno \& Stutzer, 2002; Verkuyten, 2008).

With increasing migration among countries, the adaptation of immigrants has become a critical concern for both practitioners and researchers. Life satisfaction, in this sense, is an important proxy of their adaptation as Vohra and Adair (2000) explained that it is extremely important to study their satisfaction since it indicates the extent to which they are faring in hosting countries. Immigrants' reported happiness and life satisfaction are vital to understand their overall well-being in hosting countries, and the causes of their dissatisfaction and/or unhappiness with their lives must be identified and analyzed (Vohra \& Adair, 2000). Furthermore, Tran and Nguyen (1994) explained that if immigrants have found a place of residence and are generally satisfied with their lives, then it can be stated that they have successfully adjusted to their new lives and thus, life satisfaction can be used as an indicator of immigrants' mental health status.

While an abundance of literature exists on the topic of life satisfaction, studies examining that among immigrants and/or ethnic minorities are relatively less (Verkuyten, 2008), and furthermore, studies examining life satisfaction in relation to immigrants' encounter of discriminatory events are even fewer. The existing literature on immigrants' life satisfaction commonly report lower life satisfaction (Marsiglia et al., 2013; Verkuyten, 2008; Ullman \& Tatar, 2001) and empirical evidence also points to a negative direction in association between perceived discrimination and life satisfaction among immigrants and ethnic minorities (Verkuyten, 2008; Giamo, Schmitt, \& Outten, 2012). A similar finding was yielded in Giamo et al. (2012)'s study of multiracial individuals in Canada that their perception of discrimination had negative effect on their life satisfaction.

\subsection{Present Study}

With a void in current immigrant literature on association between discriminatory experiences and life satisfaction both in Korea and abroad, this study was conducted with an aim to fill this gap by first exploring the experiences of discrimination and associated factors and second, examining the hypothesized relationship between perceived discrimination and life satisfaction among female marriage migrants. Marriage migrants refer to foreign spouses of Korean citizens, and the number of these individuals has grown drastically over the last decade. As a result of heightened social attention to this particular immigrant population, studies examining their life satisfaction and well-being in various aspects have accumulated over time. However, these studies share a common limitation as a majority of these studies, first overlooked the role of discriminatory experiences in determining their life satisfaction, and second, failed to take into consideration that the migrants are indeed an ethnically heterogeneous group with different needs and characteristics. This study therefore also aims to investigate the group differences in perceived discrimination and association between discrimination and life satisfaction with a hypothesis that the group differences exist in paths leading to both perceived discrimination and to life satisfaction. This study addresses three research questions: what are the factors associated with discrimination experiences of foreign spouses? Are their experiences of discrimination associated with their life satisfaction? And lastly, do group differences exist in discrimination experiences and its relationship to life satisfaction?

\section{Method}

\subsection{Data}

To address research questions, the National Survey on Multicultural Families 2009 was used for analyses. The Survey 2009 is the first and only complete enumeration study on a national population of multicultural families in Korea, and it contains a wide range of information from basic demographic and socioeconomic information to their service utilization behaviour and service needs. The data contains responses of 73,669 female and male migrants. For this study, however, only responses of female migrants were used as male migrants' ethnic background was not as diverse as the female migrants to conduct multiple group-analyses. Furthermore, only 
those in 'working age population (18 65 years) were included as one of the questions on discrimination experiences addresses their work experiences.

\subsection{Measures}

\subsubsection{Life Satisfaction}

The definition of life satisfaction is adopted from Inglehart (1990), 'a cognitive assessment of one's subjective well-being covering all domains of life from income, occupation, and social life' (p. 214). It was measured through one question, "how satisfied are you with your life considering all aspects of your life?" Responses were coded on a five point scale ranging from one (very satisfied) to five (very dissatisfied), and the scale was inversely re-coded, so that the higher score is indicative of satisfaction.

\subsubsection{Discrimination}

While various concepts and measurements exist in capturing discriminatory experiences, this study employed the definition of perceived discrimination; experiences of being treated differently because of their race and/or ethnicity. It was measured through five questions such as 'have you ever experienced discrimination at workplace?' and 'have you ever experienced discrimination at the store?'. The responses were coded on a five point scale from one 'was severely discriminated' to five 'never experienced discrimination'. For analyses, each response was re-coded to have a range of zero to four, so that the higher score indicates more severe or blatant discrimination.

\subsubsection{Socio-demographic Factors}

Age, length of residence, language ability, current employment status, education, income, place of residence, naturalization status, having children, and ethnic background were included as socio-demographic variables in this study. Age and length of residence were measured as continuous variables. Language ability was measured in three domains: speaking, writing, and reading abilities. It is self-rated ability and respondents were asked how fluent they are in each domain on a five point scale ranging from one (very poor) to five (very good). For the analysis, the mean of the total score of all three domains was used. Current employment status was measured through a dichotomous variable ( 0 : currently not working, 1 : currently working). A dummy code was created to measure their education to distinguish the migrants with high school or less education from those with college and above education. Income was measured by asking the migrants their monthly household income on an six-point scale ranging from zero (below one million KRW) to five (above five million KRW). Another dummy code was created for the migrant's place of residence with zero indicative of residence in rural areas and one indicating urban areas. Naturalization status and having children were measured into dichotomous variables ( 0 : no, 1: yes). Lastly, country of origin was used as a proxy of ethnic background among women, and it was measured by asking the migrants to choose the country of origin from the information booklet. To assess group differences by ethnic background, China, Japan, Taiwan, and Mongolia were grouped into East Asian countries, while Vietnam, Philippine, Cambodia, and Thailand were group into Southeast Asian countries, and the rest such as Russia and Uzbekistan were group into other countries.

\subsection{Analyses}

Analyses are mainly in three parts. First, descriptive analyses are conducted to provide overview information on foreign wives' socio-demographic factors, experiences of discrimination, and life satisfaction. Group differences on these variables by ethnic background are also explored in this stage. Secondly, the association between perceived discrimination and life satisfaction are examined using structural equation modeling. Third, the multiple group analyses are conducted to investigate whether paths leading to life satisfaction vary depending on migrants' ethnic background.

\section{Results}

\subsection{Descriptive Analyses}

As illustrated in Table 1, the mean age of the wives was $34.99(\mathrm{SD}=8.91)$, indicating that the women as whole group are relatively young. The mean years of residence in Korea is 5.93 years $(\mathrm{SD}=3.98)$. The mean score of women's language ability in all three areas (speaking, reading, and writing) was $3.39(\mathrm{SD}=1.05)$, indicating that their self-rated Korean language ability is slightly above the average. Approximately half of the women were unemployed at the time of survey with $53 \%$ and a majority of the women had less than high school education (75.8\%). A majority of the women (68.7\%) reported that their monthly household income was below one millions KRW. A large number of the women resided in urban areas with 68.2 percent. About $40.5 \%$ of the women reported that they obtained citizenship in Korea, and $64.6 \%$ of the women had one or more children 
currently living with them. As for ethnic background of the women, the largest group is women from East Asian countries such as China (both Korean-Chinese and Han Chinese), Japan, Taiwan, and Mongolia with 69.4\%, followed by women from Southeast Asian countries (Vietnam, Philippine, Cambodia, and Thailand) making up approximately $27 \%$ of the women. Women from Russia, Uzbekistan, and other countries made up the smallest ethnic group with $3.4 \%$.

When severity of discrimination experience was examined, women reported of being most severely discriminated at work place (Mean=1.63, $\mathrm{SD}=0.93$ ) while the lowest score was in the category of discrimination at real estate brokers/ by landlord (Mean=0.71, $\mathrm{SD}=0.90$ ). As for life satisfaction, the mean score was 3.52 $(\mathrm{SD}=0.91)$, indicating that the women as a group were generally satisfied.

Table 1. Descriptive statistics

\begin{tabular}{|c|c|c|c|c|}
\hline Variable & Mean & $\mathrm{SD}$ & $\mathrm{n}$ & $\%$ \\
\hline Age & 34.99 & 8.91 & & \\
\hline Length of residence & 5.93 & 3.98 & & \\
\hline Language ability & 3.39 & 1.05 & & \\
\hline Speaking & 3.46 & 1.07 & & \\
\hline Reading & 3.44 & 1.11 & & \\
\hline Writing & 3.25 & 1.28 & & \\
\hline \multicolumn{5}{|l|}{ Current employment status } \\
\hline Not working & & & 8,433 & 53.0 \\
\hline Working & & & 7,488 & 47.0 \\
\hline \multicolumn{5}{|l|}{ Education } \\
\hline Less than high school & & & 12,098 & 75.8 \\
\hline More than college & & & 3,857 & 24.2 \\
\hline \multicolumn{5}{|l|}{ Income (KRW) } \\
\hline$<1$ million & & & 8,090 & 68.7 \\
\hline $1 \sim 2$ million & & & 3,233 & 27.5 \\
\hline $2 \sim 3$ million & & & 251 & 2.1 \\
\hline $3 \sim 4$ million & & & 91 & 0.8 \\
\hline $4 \sim 5$ million & & & 36 & 0.3 \\
\hline$>5$ million & & & 73 & 0.6 \\
\hline \multicolumn{5}{|l|}{ Place of residence } \\
\hline Urban & & & 10,958 & 68.2 \\
\hline Rural & & & 5,106 & 31.8 \\
\hline \multicolumn{5}{|l|}{ Naturalization status } \\
\hline Yes & & & 6,455 & 40.5 \\
\hline No & & & 9,477 & 59.5 \\
\hline \multicolumn{5}{|l|}{ Having children } \\
\hline Yes & & & 10,255 & 64.6 \\
\hline No & & & 5,611 & 35.4 \\
\hline \multicolumn{5}{|l|}{ Ethnic background } \\
\hline Southeast Asian countries & & & 4,359 & 27.1 \\
\hline East Asian countries & & & 11,156 & 69.4 \\
\hline Russia and others & & & 549 & 3.4 \\
\hline \multicolumn{5}{|l|}{ Discrimination experiences } \\
\hline In neighborhood & 1.28 & 0.97 & & \\
\hline At restaurants/banks & 1.16 & 0.98 & & \\
\hline At public service centers & 0.88 & 0.97 & & \\
\hline At real estate brokers/landlord & 0.71 & 0.90 & & \\
\hline At work & 1.63 & 0.93 & & \\
\hline Life satisfaction & 3.52 & 0.91 & & \\
\hline
\end{tabular}


As shown in Table 2, there were differences in socio-demographic factors as well as discrimination and life satisfaction levels by ethnic groups. For example, women from Southeast Asian countries were as a group significantly younger than women from other countries, and they were the newest arrivals in Korea as the mean years of residence was 4.42 years $(\mathrm{SD}=3.13)$ while women from other countries had stayed in Korea more than six years on average. They also scored the lowest in self-rated language ability while women from East Asian countries exhibited the highest score. As for income, women from Russia and other countries reported of earning more than women from the other regions, and the difference was statistically significant.

Women from Southeast Asian countries reportedly experienced more discrimination than those from East Asian countries and others, and the difference was statistically significant. As shown in Table 2, women from East Asian countries experienced the least discrimination, and interestingly, they also reported the lowest level of life satisfaction. Women from Southeast Asian countries and Russia and others tended to be more satisfied with their lives in general in comparison.

Table 2. Differences in key variables by ethnic groups

\begin{tabular}{|c|c|c|c|c|}
\hline \multirow{2}{*}{ Variables } & \multicolumn{3}{|c|}{ Ethnic background } & \multirow{2}{*}{ Post-Hoc } \\
\hline & Southeast Asia(a) & East Asia(b) & Others(c) & \\
\hline Age & $28.53(6.85)$ & $37.65(8.39)$ & $32.37(6.41)$ & $\mathrm{b}>\mathrm{c}>\mathrm{a} * * *$ \\
\hline Length of residence & $4.42(3.13)$ & $6.51(4.15)$ & $6.13(3.47)$ & $\mathrm{b}>\mathrm{c}>\mathrm{a}^{* * *}$ \\
\hline Language ability & $1.72(.82)$ & $2.51(1.13)$ & $2.02(.85)$ & $\mathrm{b}>\mathrm{c}>\mathrm{a} * * *$ \\
\hline \multicolumn{5}{|l|}{ Current employ. status } \\
\hline (yes) & 1,931 & 5,331 & 226 & \multirow{2}{*}{$\begin{array}{c}\text { Pearson } \chi 2=20.789 \\
p<.001\end{array}$} \\
\hline (no) & 2,374 & 5,739 & 320 & \\
\hline Education & & & & \multirow{3}{*}{$\begin{array}{c}\text { Pearson } \chi 2=335.750 \\
p<.001\end{array}$} \\
\hline (less than high school) & 3,165 & 8,689 & 244 & \\
\hline (more than college) & 1,137 & 2,418 & 302 & \\
\hline Income & $.31(.88)$ & $.40(.61)$ & $.60(.95)$ & $\mathrm{c}>\mathrm{b}>\mathrm{a} * * *$ \\
\hline \multicolumn{5}{|l|}{ Place of residence } \\
\hline (urban) & 2,392 & 8,191 & 375 & \multirow{2}{*}{$\begin{array}{c}\text { Pearson } \chi 2=497.287, \\
p<.001\end{array}$} \\
\hline (rural) & 1,967 & 2,965 & 174 & \\
\hline \multicolumn{5}{|l|}{ Naturalization status } \\
\hline (yes) & 1,278 & 5,056 & 121 & \multirow[t]{2}{*}{$\begin{array}{c}\text { Pearson } \chi 2=409.130 \\
p<.001\end{array}$} \\
\hline (no) & 3,036 & 6,018 & 423 & \\
\hline \multicolumn{5}{|l|}{ Having children } \\
\hline (yes) & 3,116 & 6,719 & 390 & \multirow[t]{2}{*}{$\begin{array}{c}\text { Pearson } \chi 2=192.950 \\
p<.001\end{array}$} \\
\hline (no) & 1,173 & 4,283 & 155 & \\
\hline Discrimination & $1.05(.64)$ & $.93(.60)$ & $.98(.61)$ & $\mathrm{a}>\mathrm{bc} * * *$ \\
\hline Life satisfaction & $2.63(.97)$ & $2.47(.88)$ & $2.57(.85)$ & $\mathrm{a}=\mathrm{c}>\mathrm{b} * * *$ \\
\hline
\end{tabular}

Note: $* \mathrm{p}<.05, * * \mathrm{p}<.01, * * * \mathrm{p}<.001$,

Post-Hoc analysis using Games-Howell.

\subsection{Relationship between Discrimination and Life Satisfaction}

To examine the relationship between perceived discrimination and life satisfaction, structural path model was specified. The model yielded a chi-square value of $2094.454(\mathrm{DF}=53)$ at a probability of $<.001$, the IFI and CFI value of .935 , and RMSEA value of .049 , indicating that the current structural model fit the data adequately. As illustrated in Table 3 , the factors significantly associated with perceived discrimination are age $(\beta=-.031, p<.001)$, language ability $(\beta=-.101, p<.001)$, current employment status $(\beta=-.175, p<.001)$, women's education $(\beta=.077$, 
$\mathrm{p}<.001)$, place of residence $(\beta=-.050, \mathrm{p}<.001)$, having children $(\beta=.025, \mathrm{p}<.05)$, and ethnic background. Women from East Asian countries $(\beta=-.050, p<.001)$ and other countries $(\beta=-.027, p<.001)$ experienced less discrimination than women from Southeast Asian countries. In other words, younger women with college and above education, those who are residing in rural areas, currently unemployed, have children, and are less fluent in Korea area more likely to experience more discrimination in their daily life.

Among the determinants of life satisfaction of female migrants, perceived discrimination was a strong predictor $(\beta=-.111, p<.001)$. This significant and negative association between discrimination and life satisfaction is consistent with findings from previous studies as they commonly report of harmful effect of discrimination on immigrants' well-being. The finding also showed that women from Southeast Asian countries were generally more satisfied with their life than those from East Asian countries $(\beta=-.101, p<.001)$ and from other countries such as Russia $(\beta=-.014, \mathrm{p}>.05)$. Among all the other socio-demographic factors, language ability was a strong predictor $(\beta=.155, \mathrm{p}<.001)$, indicating that those who are more fluent in Korean language tend to be more satisfied with their life.

Table 3. Standardized estimates of discrimination and life satisfaction

\begin{tabular}{ccc}
\hline Variables & Discrimination & Life Satisfaction \\
\cline { 2 - 3 } & $\beta$ & $\beta$ \\
\hline Age & $-.031^{* *}$ & $-.071^{* * *}$ \\
Length of residence & .022 & $-.074^{* * *}$ \\
Language ability & $-.101^{* * *}$ & $.155^{* * *}$ \\
Current employment status & $-.175^{* * *}$ & -.009 \\
Education & $.077^{* * *}$ & $-.042^{* * *}$ \\
Income & .010 & $.058^{* * *}$ \\
Place of residence & $-.050^{* * *}$ & .015 \\
Naturalization status & .018 & $-.067^{* * *}$ \\
Having children & $.025^{*}$ & $-.048^{* * *}$ \\
Southeast Asia & --- & --- \\
East Asia & $-.050^{* * *}$ & $-.101^{* * *}$ \\
Others & $-.027^{* * *}$ & -.014 \\
Discrimination & & $-.111^{* * *}$ \\
\hline
\end{tabular}

${ }^{*} \mathrm{p}<.05, * * \mathrm{p}<.01, * * * \mathrm{p}<.001$

\subsection{Multiple Group Analyses: By Ethnic Group}

To examine whether paths leading to discrimination and life satisfaction differ by ethnic groups, multiple group analyses were conducted. The constrained model in which all the paths are constrained to be equal across all ethnic groups was compared to the unconstrained model in which all the paths were estimated individually, and the result yielded a statistically significant chi-square value difference $(\Delta \chi=142.10, \mathrm{df}=36, \mathrm{p}<.001)$, indicating that paths are not invariant across ethnic groups.

Illustrated in Table 4, paths leading to discrimination and life satisfaction varied across ethnic groups. For example, for paths leading to discrimination, employment status was the only factor that was consistently significant in predicting discrimination experiences among all three ethnic groups $(\beta=-.228,-.139,-.213, \mathrm{p}<.001)$, indicating that those who are unemployed tend to experience discrimination more than the employed women. For women from East Asian countries, being naturalized was significantly associated with their experiences of discrimination $(\beta=.028, \mathrm{p}<.05)$ though it did not have any association in two other groups. A difference was also detected with status of children as the association was significant only among women from Southeast Asian countries $(\beta=.044, \mathrm{p}<.05)$ and other countries $(\beta=-.120, \mathrm{p}<.05)$. For Southeast Asian women, those with children were more likely to report of discrimination experiences while for women from Russia and other countries, the association was negative, indicating that those without children are more likely to experience discrimination. 
Language ability was negatively associated with the experiences for women from Southeast Asia and East Asia as those with poor language skills were more likely to be discriminated at different places though the relationship was not significant for women from Russia and other countries.

Table 4. Standardized estimates by ethnic groups

\begin{tabular}{|c|c|c|c|c|c|c|}
\hline \multirow{2}{*}{ Variables } & \multicolumn{3}{|c|}{ Discrimination } & \multicolumn{3}{|c|}{ Life Satisfaction } \\
\hline & Southeast Asia & East Asia & Others & Southeast Asia & East Asia & Others \\
\hline Age & $.094 * * *$ & $-.064 * * *$ & -.031 & -.032 & $-.071 * * *$ & -.070 \\
\hline Length of residence & -.050 & .027 & .086 & $-.067 * *$ & $-.068 * * *$ & -.013 \\
\hline Language ability & $-.083 * * *$ & $-.105 * * *$ & .078 & $.092 * * *$ & $.166^{* * *}$ & $.113^{*}$ \\
\hline Current employ. status & $-.228 * * *$ & $-.139 * * *$ & $\begin{array}{c}-.213^{* *} \\
*\end{array}$ & $-.056^{* *}$ & .004 & .009 \\
\hline Education & $.102 * * *$ & $.068 * * *$ & -.061 & -.027 & $-.041 * * *$ & $-.106^{*}$ \\
\hline Income & $.079 * *$ & $-.031 *$ & .057 & .001 & $.082 * * *$ & $.194 * * *$ \\
\hline Place of residence & -.016 & $-.061 * * *$ & $-.140^{*}$ & $.050 * * *$ & -.002 & -.010 \\
\hline Naturalization Status & -.001 & $.028^{*}$ & -.071 & $-.052 * *$ & $-.071 * * *$ & .009 \\
\hline Having children & $.044^{*}$ & .016 & $-.120^{*}$ & $-.055 * * *$ & $-.044 * * *$ & -.020 \\
\hline Discrimination & & & & $-.113 * * *$ & $-.110 * * *$ & $-.124 *$ \\
\hline
\end{tabular}

${ }^{*} \mathrm{p}<.05,{ }^{* *} \mathrm{p}<.01,{ }^{* * *} \mathrm{p}<.001$

Discrimination was negatively associated with life satisfaction level across all three ethnic groups. For women from Southeast Asian countries, discrimination was the strongest determinant of their life satisfaction $(\beta=-.113$, $\mathrm{p}<.001)$ while for East Asian women, the strongest determinant was language ability $(\beta=.166, p<.001)$. For women from Russia and other countries, income $(\beta=.194, p<.001)$ was the strongest predictor. Another common factor appeared to be statistically significant in predicting life satisfaction across all ethnic groups was language ability that women with better language skills tend to be more satisfied with their lives than women who are less fluent.

\section{Discussion}

Immigrants as a group are vulnerable population at risk of developing serious health and mental health problems as a result of constant exposure to stressors in hosting country (Mossakowski, 2003). Foreign spouses of multicultural families in Korea are vulnerable to stress as they not only have to adjust to new language, culture, and environment, but also to value systems and practices of Korean family. Exposure to discrimination adds another layer of stress as they are constantly exposed to discriminatory behaviours and remarks across various social settings. However, literature pertaining to discrimination and foreign spouses' experiences in Korea are rather scarce and little is known about how much they are exposed to interpersonal discrimination and how such experiences affect their life in general. This study thus attempts to fill some of the gaps in immigrant literature, particularly on the topic of discrimination and life satisfaction.

The result of this study provides empirical evidence for the argument that discrimination functions as a chronic and pervasive stressor (Torres, 2009), leading to deteriorated health and mental health and quality of life. This is consistent with findings of previous studies (Kim et al., 2011; Choi, 2012; Giamo et al., 2012; Verkuyten, 2008). The finding also provides evidence that foreign spouses in Korea are indeed exposed to discrimination across various social settings, and that group differences also exist in degree to exposure to discrimination and the level of life satisfaction as well as in paths leading to life satisfaction. For example, women from Southeast Asian countries reported of being more discriminated than the women from other two regions. This finding is consistent with previous studies that individuals with different physical characteristics, such as skin tone, color of hair and eyes, and facial structure tend to experience more discrimination than those who look similar to dominant racial/ethnic group (Rumbaut, 1994; Yang, 2005). As women from China, Japan, Taiwan, or Mongolia tend to look more similar to Korean than the women from Southeast Asian countries, it is likely that they are easily identified as foreigners in various social settings, potentially making them an easy target of discrimination. 
An interesting finding was also yielded in respect to life satisfaction. First as suspected, those who are more recent arrivals in Korea were found to be more satisfied with their life than those who have stayed in Korea for a longer period of time. This finding is consistent with literature investigating healthy immigrant effect which explains that the more acculturated immigrants tend to exhibit lower level of life satisfaction, more depressive symptoms, and other health problems (Kulis, Marsiglia, \& Nieri, 2009). This is also consistent with Oberg's U-Curve theory which argues that recent immigrants first go through the honeymoon phase in which they are generally satisfied with their new life (Oberg, 1960). As immigrants adjust and become familiar with their new life, it is argued that they become aware of the extent of discrimination, their disadvantaged status as minority, and become dissatisfied with their life (Kulis et al., 2009).

Second, when ethnic differences were examined in life satisfaction, women from Southeast Asian countries exhibited the highest level of satisfaction among all groups. This may be explained by the fact that Southeast Asian women as a group are relatively recent immigrants compared to women from other countries. For example, while the influx of women from East Asian countries such as Japan and China has been rather consistent from 1980 1990's, the women from Southeast Asian countries such as Vietnam and Cambodia started to noticeably rise from mid 2000's (National Statistical Office, 2011). As a group of new immigrants, they may be less inclined to perceive themselves as victims of severe discrimination. However, the finding also points out that the experiences of discrimination were indeed the strongest determinant of life satisfaction among these Southeast Asian women. This finding indicates that they are more vulnerable to the harmful effect of discrimination than other women.

These findings provide several critical implications for social work practice with multicultural families and foreign spouses. First, discrimination is a critical factor that is significantly associated with their subjective well-being, measured by life satisfaction. This indicates that practitioners working with the women must be attentive to their perceived discrimination and its potential effect on their psychological, physical, and social adjustment and need to engage women in developing healthy coping strategies. As discriminatory experiences often lead to development of poor self-image and thus, lower self-esteem, it is essential for practitioners to address the issue with the wives as well as their family members.

In addition, policies and programs to increase awareness of Korean nationals also need to be in place. Discrimination could not be diminished or weakened by the effort of the foreign-born members of society, it must be a two-way process. However, while the programs and policies for foreign wives and multicultural families focus on foreign individuals' adjustment to Korean society, asserting the importance of one-way adjustment of foreign-born wives, programs or policies targeted to increase awareness or understanding for the diversity and different cultures are close to non-existent. With an exception of some effort made by regional education offices that offer training programs for teachers on culture diversity, programs for general public as well as service providers in medical, educational, legal fields do not exist as of present. As the findings of this study show that the foreign wives are widely exposed to discrimination at workplace and in neighborhoods, community-based education programs for Korean nationals need to be developed and implemented.

Furthermore, foreign spouses are not indeed a homogeneous group as ethnic differences were identified in their exposure to discrimination, life satisfaction, and other socio-demographic factors. The finding draws attention to critical ethnic differences. They suggest that marriage migrants and/or immigrants are not a group with similar characteristics and needs as they are often delineated and treated to be, and that there should be differentiated plans of intervention for each ethnic group. This finding also shows that the uniform approach to multicultural families and foreign spouses may not be appropriate and such one-size-fits-all approach by the government and service providers may exacerbate discrimination and associated problems for them. Thus, current pre-marriage education programs offered in Vietnam, Mongolia, and Philippines should be linked to after-marriage support programs to meet the needs of each ethnic group.

As this study was conducted using cross-sectional data, it is recommended for future research to continue to examine the relation between discrimination and life satisfaction using longitudinal data to establish causality. In addition, future research needs to examine discrimination within family and how interpersonal and structural forms of discrimination affect life satisfaction of the foreign spouses. Future investigations should also consider using various constructs of subjective well-being such as quality of life and psychological distress in examining its relation to discrimination experiences. In addition, continued research efforts should explore differences by each ethnic group, probing for example, how Korean-Chinese may differ from other Chinese and East Asian women to perceive discrimination. 


\section{References}

Alston, J. P., \& Dudley, C. (1973). Age, occupation, and life satisfaction. The Gerontologist, 13, 58-61. http://dx.doi.org/10.1093/geront/13.1.58

Alston J. P., Lowe, G. D., \& Wrigley, A. (1974). Socioeconomic correlates of four dimensions of self-perceived satisfaction. Human Organizations, 33, 99-102. http://dx.doi.org/10.17730/humo.33.1.b59881q1r24p367g

Brody, G. H., Chen, Y. F., Murry, V. M., Ge, X., Simons, R. L., Gibbons, F. X., ... Cutrona, C, E. (2006). Perceived discrimination and the adjustment of African American youths. Child Development, 77(5), 1170-1189.

Brown, C. S., \& Chu, H. (2012). Discrimination, ethnic identity, and academic outcomes of Mexican immigrant children: The impact of school context. Child Development, 83(5), 1477-1485. http://dx.doi.org/10.1111/j.1467-8624.2012.01786.x

Bruno, F., \& Stutzer, A. (2002). Happiness and economics: How the economy and institutions affect human wellbeing. Princeton, NJ: Princeton University Press.

Choi, W. (2007). A study on the social-cultural adaptation of foreign wives in Korea. The Journal of Asian Women, 46(1), 141-181.

Choi, W. S. (2012). Personal characteristics, ethnic identity, experiences of discrimination, self-esteem, and problem behavior of Korean-Japanese multicultural adolescents. Korean Journal of Family Welfare, 17(2), 49-71.

Cho, Y. A. (2011). The effect of perceived discrimination on psychological distress among North Korean refugees. Korean Journal of Counseling, 12(1), 1-19. http://dx.doi.org/10.15703/kjc.12.1.201103.1

Clemente, F., \& Sauer, W. J. (1976). Life satisfaction in the United States. Social Forces, 54(3), 621-631. http://dx.doi.org/10.1093/sf/54.3.621

Feagin, J. R., \& Eckberg, D. L. (1980). Discrimination motivation, action, effects, and context. Annual Review of Sociology, 6, 1-20. http://dx.doi.org/10.1146/annurev.so.06.080180.000245

Finch, B. K., \& Vega, W. A. (2003). Acculturation stress, social support, and self-rated health among Latinos in California. Journal of Immigrant Health, 5(3), 109-117. http://dx.doi.org/10.1023/A:1023987717921

Giamo, L. S., Schmitt, M. T., \& Outten, H. R. (2012). Perceived discrimination, group identification, and life satisfaction among multiracial people. Culturally Diverse Ethnic Minority Psychology, 18(4), 319-328. http://dx.doi.org/10.1037/a0029729

Harrell, S. P. (2000). A multidimensional conceptualization of racism-related stress: Implications for the well-being of the people of color. American Journal of Orthopsychiatry, 70(1), 42-57. http://dx.doi.org/10.1037/h0087722

Horley, J. (1984). Life satisfaction, happiness, and morale: Two problems with using subjective well being indicators. The Gerontologist, 24, 124-127. http://dx.doi.org/10.1093/geront/24.2.124

Hwang, W., \& Goto, S. (2009). The impact of perceived racial discrimination on the mental health of Asian American and Latino college students. Asian American Journal of Psychology, 5(1), 15-28. http://dx.doi.org/10.1037/1948-1985.S.1.15

Inglehart, R. (1990). Culture shift in advanced industrial society. Princeton, NJ: Princeton University Press.

Jin, M. J., Bae, S., \& Hyun, M. (2011). The effect of perceived discrimination, coping strategies, and social support on depression among Chinese students in Korea. The Korean Journal of Health Psychology, 16(4), 783-797.

Jones, C. P. (2000). Levels of racism: A theoretical framework and a gardener's tale. American Journal of Public Health, 90, 1212-1215. http://dx.doi.org/10.2105/AJPH.90.8.1212

Kalaver, J. M. (1998). The Asian Indian elderly in America. New York: Garland Publishing Inc.

Kim, H., Won, S., \& Choi, S. H. (2011). Experiences of discrimination and psychological adjustment among children of multicultural families. Korean Social Welfare Research, 42(1), 117-149. http://dx.doi.org/10.16999/kasws.2011.42.1.117

Kim, N. Y. (2007). A study of life satisfaction about international marriage of women immigrants (Unpublished master's thesis). Ehwa Women's University, Seoul, Korea. 
Kulis, W., Marsiglia, F. F., \& Nieri, T. (2009). Perceived ethnic discrimination versus acculturation stress: Influences on substance use among Latino youth in the Southwest. Journal of Health and Social Behavior, 50(4), 443-459. http://dx.doi.org/10.1177/002214650905000405

Marsiglia, F. F., Booth, J. M., Baldwin, A., \& Ayers, S. (2013). Acculturation and life satisfaction among immigrant Mexican adults. Advances in Social Work, 14(1), 49-64.

Ministry of Gender Equality and Families. (2013). 2012 National Survey of Multicultural Families. Ministry of Gender Equality and Families.

Oberg, K. (1960). Cultural shock: Adjustment to new cultural environments. Practical Anthropology, 7, 177-182.

Palmore, E., \& Luikart, C. (1972). Health and social factors related to life satisfaction. Journal of Health \& Social Behavior, 13, 68-80. http://dx.doi.org/10.2307/2136974

Pavalko, E. K., Mossakowski, K. N., \& Hamilton, V. J. (2003). Does perceived discrimination affect health? Longitudinal relationships between work discrimination and women's physical and emotional health. Journal of Health and Social Behavior, 43, 18-33. http://dx.doi.org/10.2307/1519813

Phinney, J. S., Madden, T., \& Santos, L. J. (2006). Psychological variables as predictors of perceived ethnic discrimination among minority and immigrant adolescents. Journal of Applied Social Psychology, 28(11), 937-953. http://dx.doi.org/10.1111/j.1559-1816.1998.tb01661.x

Pincus, F. L. (1996). Discrimination comes in many forms. American Behavioral Scientist, 40, 186-194. http://dx.doi.org/10.1177/0002764296040002009

Prelow, H. Z., Mosher, C. E., \& Bowman, M. A. (2006). Perceived racial discrimination, social support, and psychological adjustment among African American college students. Journal of Black Psychology, 32, 442-454. http://dx.doi.org/10.1177/0095798406292677

Rumbaut, R. G. (1994). The crucible within: Ethnic identity, self-esteem, and segmented assimilation among children of immigrants. International Migration Review, 28(4), 748-794. http://dx.doi.org/10.2307/2547157

Sanders-Phillips, K. (2009). Racial discrimination: A continuum of violence exposure for children of color. Clinical Child and Family Psychology Review, 12(2), 174-195. http://dx.doi.org/10.1007/s10567-0090053-4

Torres, L. (2009). Attributions to discrimination and depression among Latino/as: The mediating role of competence. American Journal of Orthopsychiatry, 79(1), 118-124. http://dx.doi.org/10.1037/a0014930

Tran, T. V., \& Nguyen, T. D. (1994). Gender and satisfaction with the host society among Indochinese refugees. International Migration Review, 28(2), 323-337. http://dx.doi.org/10.2307/2546735

Verkuyten, M. (2008). Life satisfaction among ethnic minorities: The role of discrimination and group identification. Social Indicator Research, 89, 391-404. http://dx.doi.org/10.1007/s11205-008-9239-2

Vohra, N., \& Adair, J. (2000). Life satisfaction of Indian immigrants in Canada. Psychology Developing Societies, 12(2), 110-138. http://dx.doi.org/10.1177/097133360001200201

Ullman, C., \& Tatar, M. (2001). Psychological adjustment among Israeli adolescent immigrants: A report on life satisfaction, self-concept, and self-esteem. Journal of Youth and Adolescence, 30, 449-463. $\mathrm{http}: / / \mathrm{dx}$. doi.org/10.1023/A:1010445200081

Yang, J. H. (2005). A study on discrimination and violence experiences of foreign migrant women in Korea (Unpublished master's thesis). Kyoung Nam University, Changwon, Korea.

Yoo, H. C., \& Lee, R. M. (2008). Does ethnic identity buffer or exacerbate the effect of frequent racial discrimination on situational well-being of Asian Americans? Journal of Counseling Psychology, 55(1), 63-74. http://dx.doi.org/10.1037/0022-0167.55.1.63

Zastrow, C. (1999). The practice of social work. Belmont: CA: Brooks/Cole.

\section{Copyrights}

Copyright for this article is retained by the author(s), with first publication rights granted to the journal.

This is an open-access article distributed under the terms and conditions of the Creative Commons Attribution license (http://creativecommons.org/licenses/by/3.0/). 